\title{
Staat digital
}

Die Digitalisierung wird immer mehr zum selbstverständlichen Teil unseres Alltags. Bezahlen, Abos abschließen und vieles mehr wird heute überwiegend digital erledigt. Da erwarten die Bürger den gleichen Komfort auch vonseiten des Staates - und werden oft enttäuscht. Hierzulande tut man sich offensichtlich schwer damit, analoge Prozesse in digitale zu überführen. Ein Paradebeispiel sind die berüchtigten Fax-Meldungen der Corona-Infektionszahlen seitens der Gesundheitsämter.

Was steht der Digitalisierung dabei im Weg? Zum Teil ist es sicher der verbreitete Konservatismus in Behörden. Wenn das Fax vor 30 Jahren gut war, warum soll es dann heute plötzlich schlecht sein? Ein anderer Aspekt ist aber sicher, dass in kaum einem anderen Land die Themen Datenschutz und Datensicherheit einen so hohen Stellenwert haben wie in Deutschland. Vieles, das technisch ohne große Schwierigkeiten umsetzbar wäre, scheitert in der Praxis daran, dass datenschutzrechtliche Bedenken geltend gemacht werden. Angesichts der deutschen Geschichte ist diese Vorsicht verständlich. Andererseits ist es etwas widersprüchlich, wenn Bürger:innen allerhöchste Ansprüche an den Schutz ihrer Daten stellen, sobald es der Staat ist, der diese verarbeiten soll, die gleichen Bürger:innen aber ohne zu zögern ihre Daten diversen privaten Internet-Unternehmen anvertrauen.

Besonders bizarr ist es aber, wenn Menschen auf Facebook posten, dass sie aus datenschutzrechtlichen Gründen die Corona-App nicht installieren werden. Da darf man dann schon ein erhebliches Defizit an Digitalbildung konstatieren.

Ich wünsche Ihnen eine erkenntnisreiche Lektüre

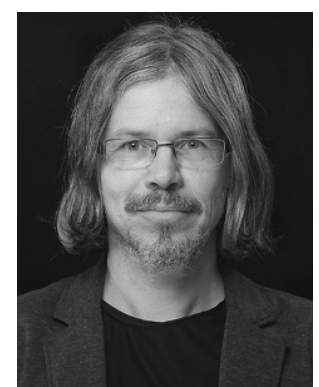

Peter Pagel $(\bowtie)$

peter.pagel@springer.com

Wiesbaden, Deutschland

Peter Pagel

Chefredakteur

Wirtschaftsinformatik \& Management 2021 • 13 (3): 169 https://doi.org/10.1365/s35764-021-00341-y

Angenommen: 19. April 2021

Online publiziert: 26. April 2021

(c) Springer Fachmedien Wiesbaden GmbH, ein Teil von Springer Nature 2021 